\title{
Women and Meritocracy in Education Discourse: Ukrainian Scenario
}

\author{
Iryna Semeniuk \\ Istanbul Sabahattin Zaim University, Turkey
}

\begin{abstract}
The article goal is to contribute to a better understanding of the modern discourse theories which have the potential for solving some of the acute theoretical problems that emerge due to the specificity of such phenomena as the discursive and communicative turn in humanities, the information society and the status of the subject of social and cultural research. We believe that the conceptual category of meritocracy in education discourse provides the basis for development of effective new models of interdisciplinary research which become more important in the situation of development of internal negative processes in the present-day humanities and social sciences.

The article considers the main line of reasoning related to the achievement of female equity in education, laying out some of the contradictions and tensions in merictocratic education discourse and policy efforts, and pointing out some of the disjunctures between policy assumptions and the complexities of household decision made in different contexts. The education of women in particular is seen as providing the key to securing intergenerational transfers of knowledge, and providing the substance of long-term gender equality and social change.

In particular the paper argues that the meritocracy through education discourse can potentially conceal inequalities and injustices in the contemporary Ukrainian society. The paper also aims to understand the floating role of women in scientific community with a special interest in the universities in Ukraine.
\end{abstract}

Keywords: female equity, female education, education discourse, meritocracy 


\section{Universal Notion of Meritocracy}

New Dictionary of Cultural Literacy (2005) defines meritocracy as "a government or society in which citizens who display superior achievement are rewarded with positions of leadership. In a meritocracy, all citizens have the opportunity to be recognized and advanced in proportion to their abilities and accomplishments. The ideal of meritocracy has become controversial because of its association with the use of tests of intellectual ability, such as the Scholastic Aptitude Test, to regulate admissions to elite colleges and universities. Many contend that an individual's performance on these tests reflects his or her social class and family environment more than ability”. The idea of meritocracy as a social system in which „merit or talent is the basis for sorting people into positions and distributing rewards" (Scully 1997, 413) has received great attention since the term was popularized in 1958 by Young (1958).

In fact the term meritocracy by itself was coined by Michael Young in his critical social satire entitled 'The rise of meritocracy' (1958). Here, Young defines merit as an individual characteristic constituting of 'intelligence and effort... $(\mathrm{I}+\mathrm{E}=\mathrm{M}$ )' (Young 1958, p. 94). Young links the emergence of a society based on 'the principle of selection by merit' (Young 1958, 24) that replaced a society where status was 'ascribed by birth' (Young 1958, 19) to changes in the British occupational structure.

Then a problem with 'merit' definition arises. McNamee and Miller (2004) think that an individual merit is generally viewed as a combination of factors including innate abilities, working hard, having the right attitude, and having high moral character and integrity. When factors associated with individual "merit" are related to income and wealth, it turns out that these factors are often not as uniquely individual or as influential as many presume. Most experts point out, for instance, that "intelligence," as measured by IQ tests, is partially a reflection of inherent intellectual capacity and partially a reflection of environmental influences. It is the combination of capacity and experience that determines "intelligence." Even allowing for this "environmental" caveat, IQ scores only account for about $10 \%$ of the variance in income differences among individuals (McNamee and Miller 2004; Fisher 1996). Since wealth is less tied to achievement than income, the amount of influence of intelligence on wealth is much less. Other purportedly innate "talents" cannot be separated from experience, since any "talent" must be displayed to be recognized and labeled as such (Chambliss 1989). There is no way to determine for certain, for instance, how many potential world-class violinists there are in the general population but who have never once picked up a violin. Such "talents" do not spontaneously erupt but must be identified and cultivated. 
According to McNamee and Miller (2004) applying talents is also necessary. Working hard is often seen in this context as part of the merit formula. Heads nod in acknowledgment whenever hard work is mentioned in conjunction with economic success. Rarely is this assumption questioned. Neither of these measures of "hard" work is directly associated with economic success. In fact, those who work the most hours and expend the most effort (at least physically) are often the most poorly paid in society. By contrast, the really big money in America comes not from working at all but from owning, which requires no expenditure of effort, either physical or mental. In short, working hard is not in and of itself directly related to the amount of income and wealth that individuals have.

Next story about attitudes here is mixed as well (McNamee and Miller 2004). First, it is not clear which particular mix of attitudes, outlooks, or frames of mind are associated with economic success. The kind of mental outlook that would be an advantage in one field of endeavor, may be a disadvantage in another field of endeavor. A different set of "proper attitudes," for instance, may be associated with being a successful artist than being a successful accountant. Second, the direction of influence is not always clear.

An example of the difficulty in discerning the impact and direction of these influences is reflected in the "culture of poverty" debate. According to the culture of poverty argument (McNamee and Miller 2004), people are poor because of deviant or pathological values that are then passed on from one generation to the next, creating a "vicious cycle of poverty." According to this perspective, poor people are viewed as anti-work, anti-family, anti-school, and anti-success. That is, if you are desperately poor, you may be forced to be present oriented. If you do not know where your next meal is coming from, you essentially have no choice but to be focused on immediate needs first and foremost. By contrast, the rich and middle class can "afford" to be more future oriented since their immediate needs are secure. Similarly, the poor may report more modest ambitions than the affluent, not because they are unmotivated, but because of a realistic assessment of limited life chances. In this sense, observed differences in outlooks between the poor and the more affluent are more likely a reflection of fundamentally different life circumstances than fundamentally different attitudes or values.

Finally, McNamee and Miller (2004) challenge the idea that moral character and integrity are important contributors to economic success. Although "honesty may be the best policy" in terms of how one should conduct oneself in relations with others, there is little evidence that the economically successful are more honest than the less successful. The recent spate of alleged corporate ethics scandals at such corporations as Enron, WorldCom, Arthur Andersen, Adelphia, Bristol-Myers Squibb, Duke Energy, Global Crossing, Xerox as well as recent allegations of misconduct in the vast mutual funds industry reveal how corporate 
executives often enrich themselves through less than honest means. White-collar crime in the form of insider trading, embezzlement, tax fraud, insurance fraud and the like is hardly evidence of honesty and virtue in practice. And neither is the extensive and sometimes highly lucrative so-called "irregular" or "under the table" economy - much of it related to vice in the form of drug trafficking, gambling, pornography, loan sharking, or smuggling. Clearly, wealth alone is not a reflection of moral superiority.

Advocates of meritocracy stress that in true meritocratic systems everyone has an equal chance to advance and obtain rewards based on their individual merits and efforts, regardless of their gender, race, class, or other non-merit factors. In the United States, for example, survey research repeatedly reveals that Americans endorse the meritocratic ethos. Most believe that meritocracy is not only the way the system should work but also the way the system does work (Kluegel and Smith 1986; Ladd 1994; Ladd and Bowman 1998).

Because meritocracy has been culturally accepted as a fair and legitimate distributive principle in many advanced capitalist countries and organizations (Scully, 1997; McNamee and Miller, 2004), scholars have sought to assess the extent to which equal opportunity and meritocratic outcomes have been successfully achieved in society (Arrow, Bowles, and Durlauf 2000; Dench 2006).

Anna Zimdars $(2007,12)$ evaluates what meritocracy means in practice to select undergraduate students based on merit. Unfortunately, beyond the ultimately narrow consensus that we wish to live in a society where advancement depends on personal effort and ability, scholars, theorists and practioners disagree on how exactly to operationalise merit (Sen 2000, 5; Arrow 2000, ix; Schwartz 2004 , 2). One may even argue that meritocracy is 'essentially contested', that is, 'the proper use of [the concepts] inevitably involves endless disputes about their proper uses on the part of their users' (Freeden 2003). Schwartz's comprehensive review of access to higher education illustrates the contested nature of the term merit in relation to making actual admissions decisions:

'Everyone agrees that applicants should be chosen on merit: the problem arises when we try to define it. Merit could mean admitting applicants with the highest examination marks, or it could mean taking a wider view about each applicant's achievements and potential' (Steven Schwartz 2004, 2).

On the one hand, Steven Schwartz seems to suggest that the 'highest examination marks' is one possible operationalisation of merit. On the other hand, the idea that a wider view (contextual factors) is needed leads to the contrasting implication; namely that examination marks alone are not an appropriate proxy of an applicant's merit. Figure 1 is designed by Anna Zimdars $(2007,15)$ to aid the 
understanding of Schwartz's observation by mapping the theoretical normative working of the meritocracy by showing the relationship between social origin, ability, effort, merit and outcomes.

Figure 1: The theoretical model of meritocracy

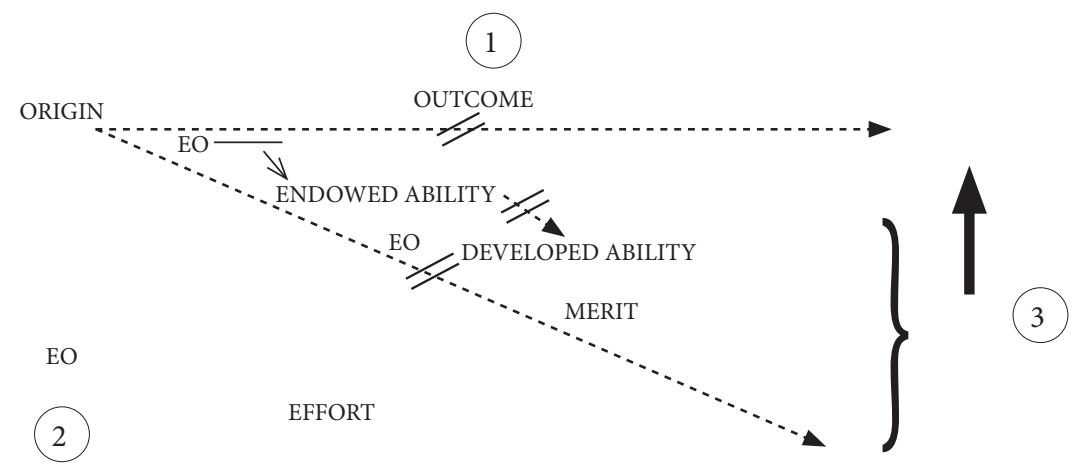

Key: EO - Equal Opportunities required; $\neq$ does not affect, EO - Equal Opportunities not given; $1,2,3$ points of empirical study

The figure shows that in meritocracies, there is a legitimate link (3) between merit and outcomes. An example of an outcome would be labour market destination - the most rewarding or powerful employment positions, or both, should be awarded to the most meritorious individuals. Merit, however, should normatively not be influenced by social origin. When Schwartz states that wider considerations might be necessary to generate the outcome 'university admission' for applicants, he is saying that educational attainment as a proxy of merit contains measurement errors because there is in fact a link (2) between social origin characteristics and merit. This could mean that the same examination attainment achieved in different social or schooling contexts may actually be the result of different underlying levels of ability and effort. The same mark may therefore hide differences in latent ability or 'potential' because not everyone had the same opportunities to shine (Zimdars 2007, 16).

This brings the discussion to the concept of equal opportunities and merit is viewed as a property relative to opportunities, which is a precondition for the smooth and uncontroversial working of meritocracy-based society. It means that 'people with the same academic aptitude or ability should be given equal access to advantaged sectors of education' (Heath 2006, 3). Factors that might affect how an individual's efforts translate into achievement should be 'regulated as to neutralize external influences' (Habermas 1976, 81). Nonetheless, there is a large 
body of empirical work that shows that actual chances to succeed in education are structured by social background factors (Breen and Goldthorpe 1999).

\section{Meritocracy and Ukrainian Education System}

The modern meritocratic process in education in Ukraine is pre-conditioned by a number of factors in the sphere of politics, having both synchronic and diachronic character: processes of recruitment; incorporation and rotation in the higher echelons of power; increasing effect of the heritage of the traditional tribal society; decreasing inertia of the Nomenklatura of the Soviet past (Kim German 2010). The mechanisms of incubation, selection and acceleration of the rising generation in the state elite have not lived up to the expectations. As a result the issue of the quality level of the new generation elite in Ukraine remains unsolved. Lack of a constructive dialogue between the political elite in power and academic elite is blocking one channel of rotation (Hrycak 2001). Meritocratic studies in neighboring Post Soviet countries are in the process of becoming a separate academic area. As for Ukraine it is just an embryo. The initiation and development of this area of study, which has a great practical importance, depends both on the willingness of the state and the determination of committed researchers and enthusiasts. The agenda includes the establishment of a specialized academic subdivision (departments, sectors, centers) for the study of topical issues of formation and the functioning of the academic meritocratic elite in Ukraine.

\section{Mapping the Meritocracy Policy of Education Discourse}

The goal of the universal meritocratic education in developing countries like Ukraine has grown out of the recognition of the importance of equipping nations and individuals owning capacities and tools required to respond to the demands of changing economic structures. In particular, the rapidly changing patterns of employment and skills requirements in the global economic system have a great influence on education systems. The intrinsic value of education is also emphasized in terms of how it increases the political awareness of individuals (Jenkin 2012; Hrycak 2001). Investing in education is one of the fundamental ways which can help the nation improve social and economic standards of living.

Gaps between male and female participation in the academic sphere and higher education are common to both developing and industrialized countries (UNESCO 1995). While they may be narrowing in some cases, persistent gender 
stereotyping results in women being segregated into specific areas of study, which further reinforces norms regarding appropriate social and economic roles for women that discriminate against them in gaining access to jobs on an equal basis with men. Ukraine is not an exception. Women are typically encouraged to pursue humanities, education and health sciences, whereas men are pushed toward education in mathematics and the sciences, which have a strong vocational link (Saith and Harriss-White 1998). Thus, even where women break barriers in terms of access to tertiary education, cultural norms shaping their relationship to the wider world of economic opportunity are not necessarily left behind.

\section{Meritocratic University and Women}

The idea that our social world and working life are becoming individualized has been under discussion for a few decades (Beck 2000; Bauman 2001). Some participants in the debate have regarded the change as positive (Castells 2004), and have glorified individual freedom, the creativity it produces and the rise of the new knowledge economy. However, ideas relating to individualization, such as the idea that market risks are now taken by the employee rather than the employer, have critical potential (Beck 2000; Nikunen 2012; Bauman 2001). Even stronger arguments have been made by Sennett (1998), who suggests that the loosening of the ties between work and the individual leads to the corrosion of character'. Thinkers on both sides of the debate have been accused of overemphasizing change over continuity (McDowell 2008).

Minna Nikunen (Nikunen 2012: 715-725) argues that while there are also continuities in academic work, the individualization associated with neoliberalism is a crucial factor. In order to emphasize current policy, the neoliberal agenda to transform welfare society has been called 'enterprise culture'. Institutions such as universities should be more like enterprises, and individuals should act like entrepreneurs. Both individualization and enterprise culture foster the meritocratic ideal.

Meritocracy means that career advancement and rewards depend on merit. However, many regard meritocracy as no more than an ideal, since one's academic career and success are affected by more than just one's individual achievements (Bagilhole and Goode 2001; Bryson 2004a). There are many forms of support - peers, colleagues, superiors, supervisors, mentoring, networks and so on - and reputation and recognition are connected to support and patronage from senior colleagues (Bryson 2004b).

Sometimes it is not easy for contract researchers to gain recognition, even when they are research active. One reason for this is that it is often the project 
leaders who get the credit for 'their' researchers' work. In relation to gender, it has been claimed that it is easier for men to get this kind of support and to gain recognition (Bagilhole and Goode 2001).

Furthermore, the degree of support one receives from home and intimate relationships is also gendered, partly because of men's and women's different obligations at home (Clegg 2008). While the ideal of meritocracy rests on the idea that everyone is equal, in reality people do not have the same obligations or starting points. Questions of affirmative action, equality, childcare and work/ life balance can therefore become problematic when viewed through the lens of this ideal (Lynch, Crean, and Moran 2010).

\section{A Modern Ukrainian Female Academic}

We aim to understand the role of female academic in scientific community in Ukraine and more specifically what it means to be a woman in Ukrainian academia.

The role of gender norms is visible in the studies as feminization of field of research. According to findings, in Ukraine female academics tend to choose to be in the fields of education, literature, humanities and social sciences which are believed to be much more suitable for women. Other fields such as engineering, medicine and fields about agriculture are highly masculinized which means the proportion of female academics is much lower than the male academics in those areas of research. This fact can be counted as the ritualization of everydayness because the female academics even at the beginning at their career follows the routes that their parents and may be more broadly speaking the society and choose a feminized topic to research (Akşit 2014).

Female scientists are of the utmost importance due to the fact that the majority of linguists in Ukraine are women. Indeed, up to sixty percent are women, and most of them work as researchers. They hold positions all the way to the top but there is still few women holding high position. Even if the majority of linguists in Ukraine are women, there are some problems regarding gender inequality in the Ukraine, but there are also chances of improvement.

In Ukraine, like in Turkey, gendered division of labour at home can be characterized as the tasks that require much bodily and mental power are expected to be done by men and women who are believed to be more delicate, less powerful and more emotional than man are expected to be caring mothers, good cooks and impassionate and loyal wives (Akşit 2014).

The role conflict that most of the Ukrainian female academics face still exist. The notion of role conflict is very parallel to the role of gender norms 
and means "the conflict between the academic career and family roles". According to Ozkanli, majority of female academics try to find a solution for this dividedness either by becoming distant from the traditional family roles or taking both the academic and domestic "workload" (Ozkanli 2007, 68). However the result is either an unhappy family life or a decrease on academic performance. Ozkanli defines the latter as abandoning administrative tasks such as dean's office, presidency of the university, thesis supervising; conduction less research and as a result a decrease in the number of scholarly work for publishing in order to be able to spend more time for family. Ozkanli explains the relative highness of the number of male academics in the administrative positions and their success in the academic performance by the role conflict (Ozkanli 2007).

The idea of role of norms, on the other hand, exists in all of the scholarly works, which are examined throughout this study. The existences of norms, gender norms in Butler's words, were highlighted above, in the beginning of this section.

As it is stated gender bounded preferences, this is reflected upon the feminization/masculinization of some special fields of research or gender division of labour in the household. Thus the lower percentage rates of women working in high level administrative positions in Turkey, mentioned above, as such roles contradict with the role of women in the household, as mother, or wife (Ozkanli 2006).

Nonetheless, the problem of feminization/masculinization of some special fields of research, as mentioned above, brings forth another, yet equally important problem of the role of women in the chief positions within the universities in Turkey as well in Ukraine. There is an uncodified tendency in Ukrainian universities that throughout time, the academics selected to be in a senior positions such as being a rector and/or vice rector are mostly from masculinized fields of research (Ozkanli 2010). Nonetheless, the percentage of female academics being in a senior position i.e. Presidency of the university is relatively low, compared to the universities worldwide.

Moreover, in everyday life there are more inequalities and also pressure on women. Women are expected to mostly dedicate themselves to their family and put their work in the background. This social role, that women have to play, takes a lot of time and most women can't focus on their career development.

In Ukraine, meritocratic ideas have not impacted upon women's work/ family (or work/life) balance or on ideals of motherhood to the same extent as, for example, in the UK: women in Ukraine are not so strongly encouraged to leave the home in favour of paid work. Furthermore, mothers with careers are criticized in the media for being selfish, and they are expected to take at least one 
year's family leave. These familial norms are applied to mothers irrespective of education or class background (Nikunen 2012, 716-717). Academic women may experience normative pressure to take long periods of leave, and men to take at least paternity leave - but good day care provision and the values of academic work also play a role. Furthermore, academic workers' perceptions of their own employability (including the security of their existing positions) and questions of money also affect their decision-making.

Moreover women suffer the brutt of oppressive social notions which expects them to marry by a specific time, no later than 25 years old. This social code implies that people do not pay attention to whether or not a woman really wants to be engaged so early on in her life. Society is less concerned about her career or academic achievements. As a consequence, feelings of inferiority and depression appear in women who do not conform to the norm.

Nonetheless, nowadays there is a growing number of female scientists and researchers who don't want to fold under social rules because they would like to be successful in their career and be a model for other women (Vlasenko, N.S., Vinogradova, Z.D., and I.V. Kalachova (2000).

\section{Conclusions and Future Study}

The merit-based women education in Ukraine is seen as key means of securing gender equality in the society. Gendered meritocratic discourses have the power to create categories that structure society, and often determine how people navigate a wide range of social, legal, and economic interactions. I believe that meritbased education discourse is getting stronger in our society, and that classical university values can also be integrated with it: they are not as diametrically opposed as it is sometimes presented. Academic freedom can take new forms under conditions of precariousness. Furthermore, the idea of meritocracy - also deeply individualist - is easily incorporated into the university system. Institutions such as universities should be more like enterprises, and individuals should act like entrepreneurs. Both individualization and enterprise culture foster the meritocratic ideal.

\section{References}

Akşit, G., and Varışlı B. 2014. Academıc Female Subject Amıdst Bourdıeu’s "Habıtus" And Butler's "Performatıvity" // TC. Maltepe Üniversitesi Fen-Edebiyat Fakültesi Dergisi 2014/1. - Istanbul, 32-43. 
Arrow, K. J., Bowles, S. and Durlauf S. 2000. Meritocracy and Economic Inequality. Princeton, NJ: Princeton University Press.

Bagilhole, B., and Goode J. 2001. The contradiction of the myth of individual merit and the reality of patriarchal support system in academic careers. European Journal of Women's Studies, 2, 161-80.

Bauman, Z. 2001. Liquid modernity. Cambridge: Polity Press.

Beck, U. 2000. The brave new world of work. Cambridge: Polity Press.

Bryson, C. 2004a. What about the workers? The expansion of higher education and the transformation of academic work. Industrial Relations Journal, 35 (1), 38-57.

Bryson, C. 2004b. The consequences for women in the academic profession of the widespread use of fixed term contracts. Gender, Work and Organization, 11 (2), 187-206.

Chambliss, W. 1989. The Mundanity of Excellence. Sociological Theory, 7, 70 -86.

Castells, M. 2004. The power of identity. The information age. Economy, society, and culture. Vol. 2., 2nd ed. Malden, MA: Blackwell.

Clegg, S. 2008. Femininities/masculinities and a sense of self: Thinking gendered academic identities and the intellectual self. Gender and Education, 20 (3), 209-21.

Dench, G. 2006. The Rise and Rise of Meritocracy. Oxford: Blackwell.

Er, D. 2008. A Sociological Approach to the Situation and Problems of the Academic Women in the Modern Turkey, Unpublished Doctoral Dissertation, Firat University, Elazig, Turkey.

Fischer, C., Hout. M, Jaankowski. M, Samuel R. , Swidler, L., and Voss, K. 1996. Inequality by Design: Cracking the Bell Curve Myth. Princeton, NJ: Princeton University Press

German, K. 2010. Peculiarities of Diasporic Elite Formation in the Post-Soviet Space. Первая международная конференция Института иентрально-азиатских исследований Хангук университета иностранных языков «Power Elites in Central Asia and Caucasus. 23-24 April, Seoul, 39-55.

Jenkin, F. 2012. Singing the Post-Discrimination Blues: Notes for a Critique of Academic Meritocracy. Retrieved from http://www.bhamlive.bham.ac.uk/schools/ptr/ departments/ philosophy/ events/2012/women-in-philosophy.aspx

Habermas, J. 1976. Legitimation crisis. London: Heinemann.

Heath, A. 2006. Equality of Opportunity, University of Oxford.

Hrycak, A. 2001. The Dilemmas of Civic Revival: Ukrainian Women since Independence. Journal of Ukrainian Studies, (Summer-Winter 2001), 1-2, 135-158.

Korpi, T., and Levin H. 2000. Precarious footing: Temporary employment as a stepping stone out of unemployment in Sweden. Work, Employment and Society, 15 (1), 127- 48.

Kluegel, J. R., and Smith E. R. 1986. Beliefs about Inequality: American's Views of What Is and What Ought to Be. New York: de Gruyter.

Ladd, E. C. 1994. The American Ideology. Storrs, CT: Roper Center for Public Opinion Research.

Ladd, E. C., and Bowman K. H. 1998. Attitudes toward Economic Inequality. Washington, DC: EI Press.

Ozkanli, O. 2007 ‘The Situation of Academic Women’ Education and Science, 32 (144): 59-70. 
Lynch, K., Crean M., and Moran M. 2010. The university as a site of struggle. In Routledge international handbook of the sociology of education, ed. M.W. Apple, S.J. Ball and L.A. Gandin, London: Routledge, 296-305.

McDowell, L. 2008. The new economy, class condescension and caring labour: Changing formations of class and gender. Nora, 16 (3), 150-65.

McNamee, S. J., and Miller, Jr. 2004. The Meritocracy Myth. Lanham, MD: Rowman and Littlefield.

Nikunen, M. 2012. Changing university work, freedom, flexibility and family. Studies in Higher Education, 37 (6), 713-729.

Saith, R., Hariss-White, B. 1998. Gender Sensitivity of Well-Being Indicators. Discussion Paper, 95, UNRISD, Geneva.

Scully, M. 1997. Meritocracy / P. H. Werhane and R. E. Freeman (eds.), Blackwell Encyclopedic Dictionary of Business Ethics: Oxford: Blackwell, 413-414.

Sen, A. 2000. Merit and Justice. Meritocracy and Economic Inequality. K. J. Arrow, S. Bowles and S. N. Durlauf. Princeton: Princeton University Press, 5-16.

Sennett, R. 1998. The corrosion of character: The personal consequences of work in the new capitalism. New York: Norton.

Schwartz, P. 2004. Fair Admissions to Higher Education: Draft Recommendations for Consultation, Schwartz Commission.

United Nations Educational, Scientific and Cultural Organization (UNESCO). 1995. Third World Education Report, UNESCO, Paris.

Vlasenko, N.S., Vinogradova, Z.D., and Kalachova I.V. 2000. Gender statistics for monitoring the progress in the area of equality between women and men: Ukraine (2000). Cabinet of Ministers of Ukraine; State Committee of Statistics of Ukraine; UNDP "Promoting Gender Equality” Project. Kiev: V.M. Koretsky Institute of NAS of Ukraine, 2000, 1-52.

Young, M. 1958. The rise of the meritocracy, 1870-2023: an essay on education and equality. London, Thames and Hudson.

Zimdars, A. 2007. Challenges to Meritocracy? A study of the social mechanisms in student selection and attainment at the University of Oxford Anna New College DPhil thesis, Trinity Term. 